\title{
PHARMACOLOGICAL, MORPHOLOGICAL AND BEHAVIORAL ANALYSIS OF MOTOR IMPAIRMENT IN EXPERIMENTALLY VITAMIN C DEFICIENT GUINEA PIGS
}

\author{
Reinaldo Barreto Oriá1, Carlos Maurício de Castro Costa², \\ Terezinha de Jesus Teixeira Santos ${ }^{3}$, Carlos Meton de Alencar G. Vieira ${ }^{4}$
}

\begin{abstract}
The scurvy shows an inflammatory disease and gingival bleeding. Nevertheless, in an animal model for guinea pigs, described by Den Hartog Jager in 1985, scurvy was associated with a motor neuron disease with demyelinization of the pyramidal tract, provoking neurogenic atrophy of muscles. Aiming at searching the protective role of vitamin $C$ in nervous system, a pharmacological, morphological and behavioral study was conducted. Three experimental groups were used: A100, animals receiving $100 \mathrm{mg} /$ vitamin C/ day; A5.0, animals receiving $5.0 \mathrm{mg} /$ vitamin $\mathrm{C} /$ day; and $\mathrm{A} 0$, animals without vitamin $\mathrm{C}$. We analyzed the weight gain, muscular diameter and behavioral tests. In all tests examined, we found significant differences between the supplemented groups in comparison with scorbutic group $(p<0.05)$. Thereafter, the animals were killed for histopathology of gastrocnemius muscle, spinal cord and tooth tissues. In addition, a morphometric study of periodontal thickness and $\alpha$-motor neuron cell body diameter were done. The vitamin C-diet free regimen seemed to induce a disruption in spinal cord morphology, involving the lower motor neuron, as confirmed by a significant reduction in neuron perycaria diameter and muscular atrophy, complicated by increased nutritional deficit.
\end{abstract}

KEY WORDS: vitamin C, ascorbic acid, motor neuron disease, guinea pig, motor behavior.

\begin{abstract}
Análise farmacológica, morfológica e comportamental do comprometimento motor em cobaios com deficiência de vitamina $C$ induzida experimentalmente

RESUMO - O escorbuto se caracteriza por doença inflamatória e sangramento gengival. Contudo, num modelo animal em cobaios, descrito por Den Hartog Jager em 1985, o estado escorbútico foi associado à doença do neurônio motor com desmielinização do trato piramidal, provocando atrofia neurogênica dos músculos. Objetivando investigar o papel protetor da vitamina C no sistema nervoso, um estudo farmacológico, morfológico e comportamental foi conduzido. Três grupos experimentais foram usados: A100, animais recebendo $100 \mathrm{mg} /$ vitamina C/ dia; A5,0, animais recebendo 5,0 mg/ vitamina C/ dia; e A0, animais sem vitamina C. Nós avaliamos o ganho de peso, diâmetro muscular e realizamos testes comportamentais. Em todos os testes examinados, detectamos diferenças significantes dos grupos suplementados em relação ao grupo escorbútico $(p<0,05)$. Os animais foram sacrificados para histopatologia do músculo gastrocnemius, medula espinhal e tecidos dentários. Também foi realizado estudo morfométrico da espessura do periodonto e do diâmetro dos corpos celulares dos neurônios motores $\alpha$. A carência de vitamina C parece comprometer a morfologia da medula espinhal envolvendo o neurônio motor inferior, confirmada pela redução significativa do diâmetro dos pericárions e atrofia muscular, complicada pelo aumento do déficit nutricional.
\end{abstract}

PALAVRAS-CHAVE: vitamina C, ácido ascórbico, doença do neurônio motor, cobaio, comportamento motor.

Vitamin $C$ is an essential nutrient for human beings and few other species that do not have the enzymatic system L-gulono- $\gamma$-lactone oxidase, the final step in ascorbic acid biosynthesis pathway, catalyzing the conversion of L-gulono- $\gamma$-lactone to ketogulono- $\gamma$-lactone ${ }^{1,2}$. Ascorbic acid is synthesized in the liver of mammals capable of its synthesis or in the kidney of reptiles and amphibians. The ancestors of primates had lost their ascorbate synthesizing ability during the evolution owing to mutations in the gulono-lactone oxidase gene ${ }^{1}$. The identification of an animal model for ascorbic acid deficiency was carried out by Holst \& Frölich in 1907, who accidentally produced scurvy in guinea pigs and thus provided a useful animal test for studies of the repercussion of vitamin C deficiency.

Laboratory of Experimental Neurology and Neurophysiology, Department of Physiology (DFF) and Pharmacology, Federal University of Ceará (UFC) Fortaleza CE, Fortaleza CE, Brazil: ${ }^{1} \mathrm{MsC} ;{ }^{2} \mathrm{MD}$, MsC, PhD; ${ }^{3}$ Pharmacist, MsC, PhD; ${ }^{4} \mathrm{MD}$.

Received 19 June 2002, received in final form 12 September 2002. Accepted 17 September 2002.

Dr. Reinaldo Barreto Oriá - Laboratório de Neurologia Experimental e Neurofisiologia/DFF/UFC - Rua Cel. Nunes de Melo, 1127- 60430-270 Fortaleza CE, Brasil - FAX: 55852888333. E-mail: oriarte@uol.com.br 
Ascorbic acid has been implicated in a myriad of biological actions, most of them related to defective collagen synthesis seen in a scurvy status ${ }^{3,4}$. Moreover, ascorbic acid participates in a variety of enzymatic reactions (e.g. collagen and catecholamine synthesis) as an electron donor, and it has a role in redox dynamics as one of the most important water-soluble antioxidants of the mammalian tissues ${ }^{1,5-7}$. The high concentrations of this compound in central nervous system (CNS), however, suggest that ascorbic acid is a crucial factor for the antioxidant network as a scavenger of reactive oxygen species in intracellular and extracellular compartments, performing a neuroprotective role under physiological and pathological conditions ${ }^{8-10}$.

Up to date, the recent new data have showed the role of L-ascorbic acid as an important neuromodulator in glutamatergic transmission by a heteroexchange mechanism in the vicinity of the nervous tissue and so contributing to reduce the glutamate excitotoxic action in synaptic cleft ${ }^{5,11-13}$. The altered glutamate metabolism and disruption in carrier proteins, jeopardizing its elimination, can overstimulate excitatory aminoacid receptors, inducing a lethal calcium influx at a post-synaptical level ${ }^{14,15}$. Glutamate seems to trigger the release of ascorbate from primary cultures of cerebral astrocytes, which are the most abundant cell in the brain ${ }^{16}$. There is a increasing evidence that the specific loss of GLT-1 glutamate transporter in astroglial cells could contribute or even figured as a direct causal factor leading to disruption of motor neurons ${ }^{12}$. In addition, the glucose and glutamate transport impairment in cortical synaptosomes from $\mathrm{Cu} / \mathrm{Zn}$-SOD mutant mice exacerbated ischaemic brain injury by a possible toxic product, generated from the mutant. That toxic action could be increased by the oxidative insult ${ }^{10,17}$.

The scurvy status shows as a cardinal manifestation an inflammatory disease with periodontal apparatus involvement ${ }^{18,19}$. Nevertheless, in an experimental animal model described by Den Hartog Jager $(1985)^{20}$, the scurvy picture was associated with a motor neuron disease, with demyelinization of the pyramidal tract and consequent muscular atrophy. Aiming at investigating the vitamin $\mathrm{C}$ deficiency impact in the decline of motor abilities, we carried out a pharmacological, behavioral and morphological study in guinea pigs, also comparing the benefice of ascorbic acid supplementation.

\section{METHOD}

\section{Materials and treatment regimen}

The subjects were young adult guinea pigs (250-350 g) obtained from HEMOCE (Hematology and Hemotherapy Center of Ceará, Northeastern Brazil). They were housed in individually cage in an animal holding room, installed in Department of Physiology and Pharmacology of Federal University of Ceará, with $12 \mathrm{~L}: 12 \mathrm{D}$ cycle, food and water were available ad libitum.

During the experimental period, the guinea pigs were fed with an ascorbate deficient diet (Fri-Ribeâ; see Table 1). The animals were randomly divided into three experimental groups. A100 group $(n=8)$, with animals receiving $100 \mathrm{mg} /$ vitamin C/day; $A 5.0$ group $(n=8)$ with animals receiving $5.0 \mathrm{mg} /$ vitamin $C /$ day and $A 0(n=8)$, vitamin $C$ diet-free group. The supplementation was carried out by orogastric probe, immediately after its preparation. The experimental time course was 26 days, (enough time to induce the scurvy state in non supplemented guinea pigs).

\section{Experimental devices and protocols}

Motor parameter - During two days intervals, it was done measures of the muscular right thigh diameter by an electronic digital caliper (Starrett ${ }^{\circledR}$ ), just bellow the coxo-femoral joint as a muscular activity paradigm in vivo, with careful proceeding to avoid the muscular mass compression.

Behavioral analysis - In the end of the 26 days, motor behavior tests were conducted in a large open box $(50 \times 50 x$

Table 1. Composition of ascorbate deficient laboratory Fri-Ribe ${ }^{\circledR}$ diet, containing $12 \%$ moisture (maximum), 17\% crude protein (minimum), 2\% fat (minimum), 12\% fibrous matter (maximum), $15 \%$ mineral matter (maximum), $1.55 \%$ calcium (maximum), and $0.50 \%$ phosphorum (minimum).

\begin{tabular}{|c|c|}
\hline Vitamin A & $10,000 \mathrm{IU}$ \\
\hline Vitamin $D_{3}$ & $1,300 \mathrm{IU}$ \\
\hline Vitamin E & $50 \mathrm{mg}$ \\
\hline Vitamin $\mathrm{K}$ & $2 \mathrm{mg}$ \\
\hline Vitamin $B_{1}$ & $3 \mathrm{mg}$ \\
\hline Vitamin $B_{2}$ & $5 \mathrm{mg}$ \\
\hline Vitamin $B_{12}$ & $30 \mathrm{mcg}$ \\
\hline Pantothenic acid & $17 \mathrm{mg}$ \\
\hline Nicotinic acid & $40 \mathrm{mg}$ \\
\hline Folic acid & $1 \mathrm{mg}$ \\
\hline Choline & $300 \mathrm{mg}$ \\
\hline Iron & $50 \mathrm{mg}$ \\
\hline Copper & $10 \mathrm{mg}$ \\
\hline Manganese & $50 \mathrm{mg}$ \\
\hline Cobalt & $1.5 \mathrm{mg}$ \\
\hline Zinc & $0.1 \mathrm{mg}$ \\
\hline
\end{tabular}


$25 \mathrm{~cm}$ ) with a transparent Perspex front panel. In order to facilitate the behavioral measurements, animals were videotaped (Panasonic, NV-RJ16BR, video camera with zoom lens) in a dark and silent room. The video camera was positioned directly in front of the Perspex window at the front of the box. Videotapes were played using a Panasonic NV-SD video recorder. Animals from the experimental groups were videotaped automatically for $15 \mathrm{~min}$. In absence of people in the room, three behavioral variables were measured for all animals: (1) Climbing, (2) Running and (3) Rearing. All observations displayed in a video monitor were analyzed in a IBM-PC computer with a MS-DOS program named Comporta, designed for behavioral testing by Prof. Marcus R. Vale from Federal University of Ceará, where a standardized key from computer keyboard yielded a behavior pattern registry.

Autopsy procedures - Guinea pigs were killed under chloral hydrate anesthesia by formaldehyde infusion just after a carotida cannulation. The direct infusion in blood stream aimed to improve the fixation quality of the specimens. Samples were taken from the gastrocnemius muscle, superior incisors with maxillary bone and from the spinal cord, at the thoracic level, after tissue-wash in physiological solution.

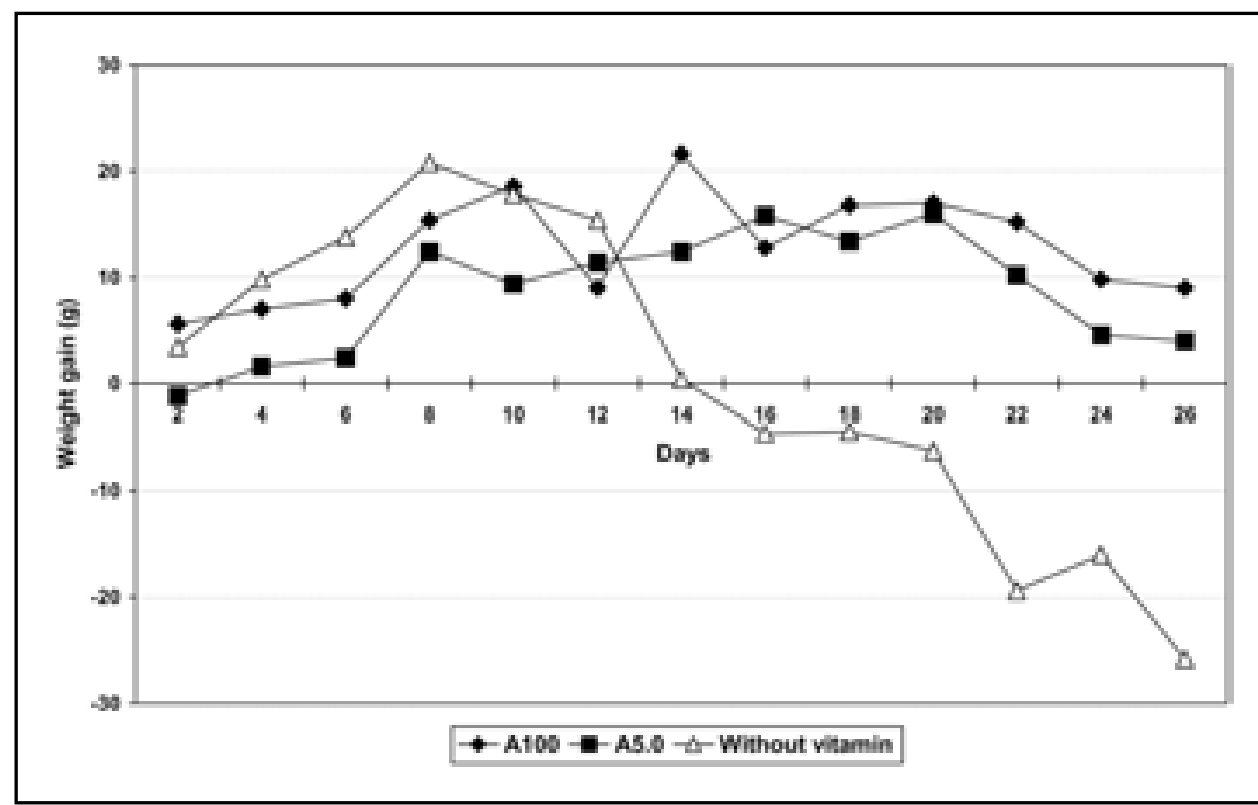

Fig 1. Curves of body weight in guinea pigs during 26 days of the experimental period.

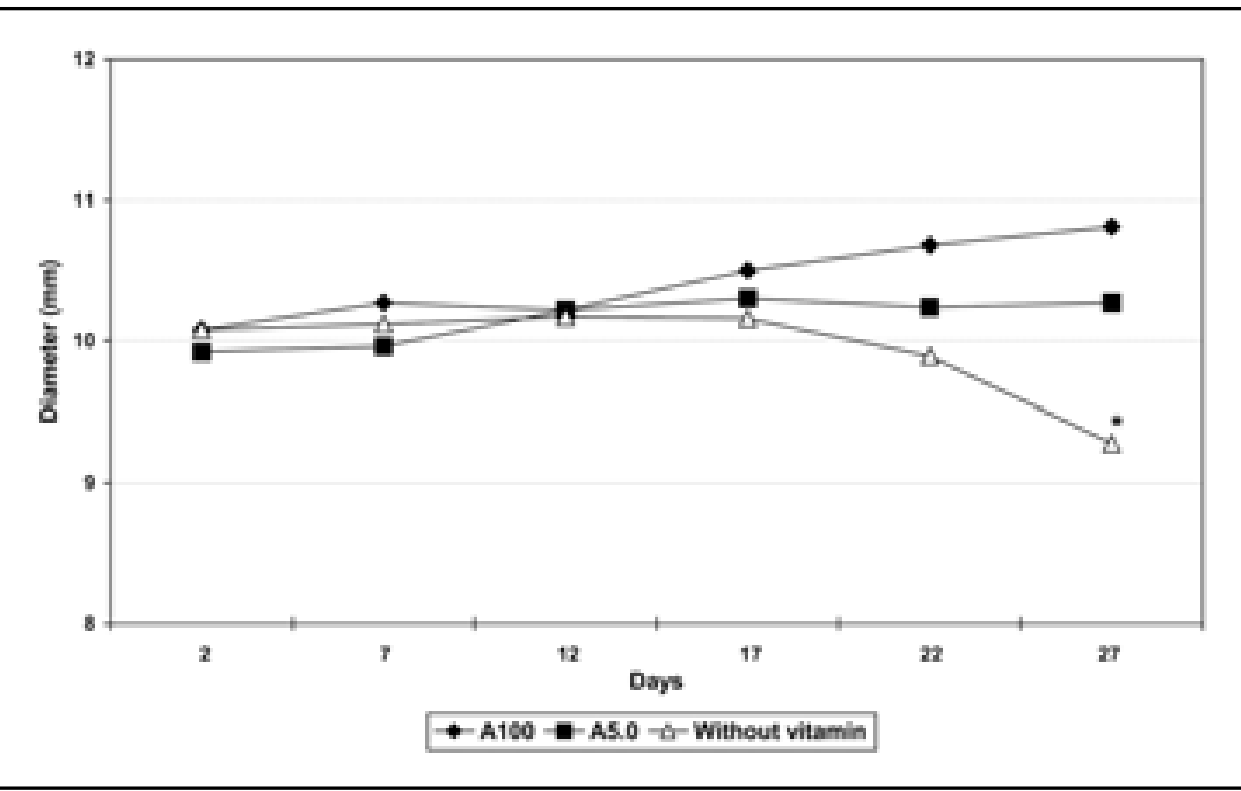

Fig 2. Guinea pigs from $A 0$ group showed a significant reduction in mean diameter from right tight only in the last days of the experimental period, confirmed by two-days interval measurements. Difference is significant at ${ }^{*} p<0.05$ by unpaired Student- $t$ test. 


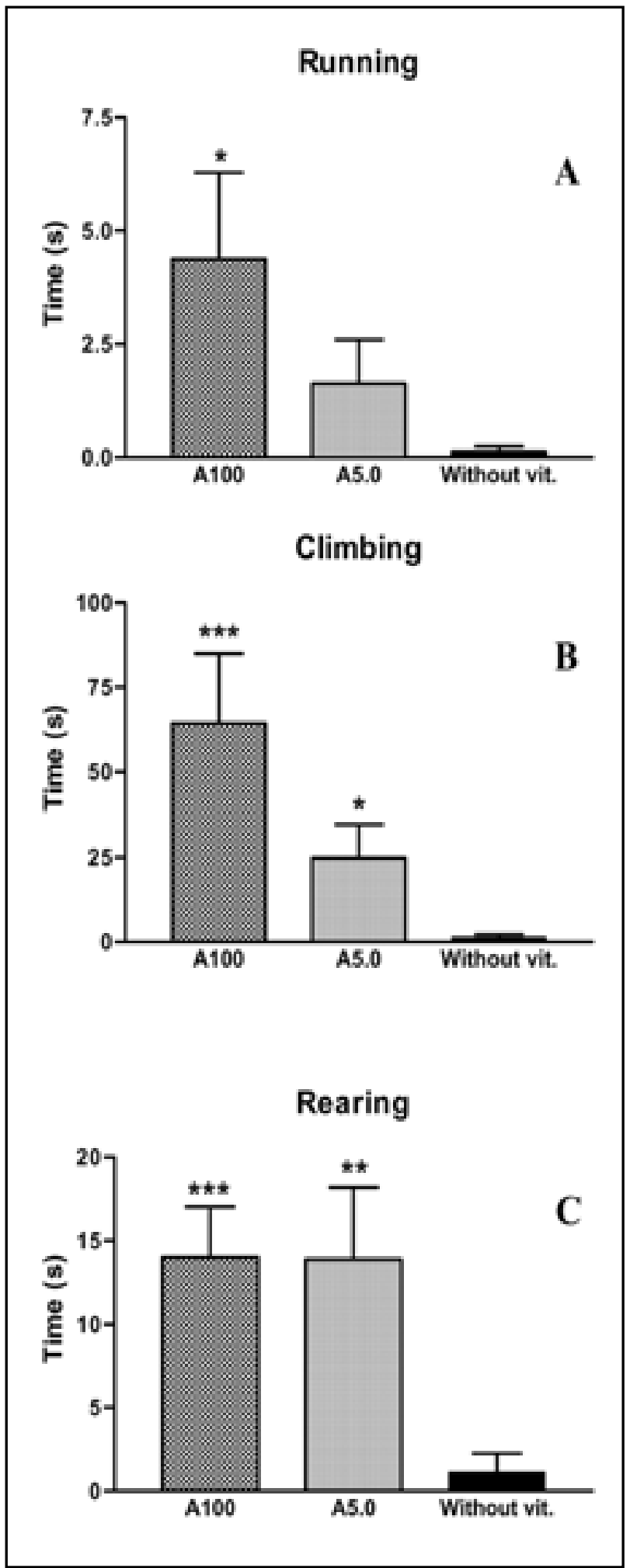

Fig 3. Non-supplemented guinea pigs (full filled bars) exhibit less motor abilities in relation to $A 100$ and $A 5.0$ supplemented groups as seen by the significant reduction in Running (A), Climbing (B) and Rearing $(C)$ behaviours during 15 min of observation period. Mean ( \pm SEM) of the guinea pigs' behaviour time in experimental groups $(n=8)$. Difference is significant at ${ }^{*} p<0.05,{ }^{* *} p<0.01$ and ${ }^{* * *} p<0.001$ by Mann-Whitney test. Vertical bars indicate the standard error mean

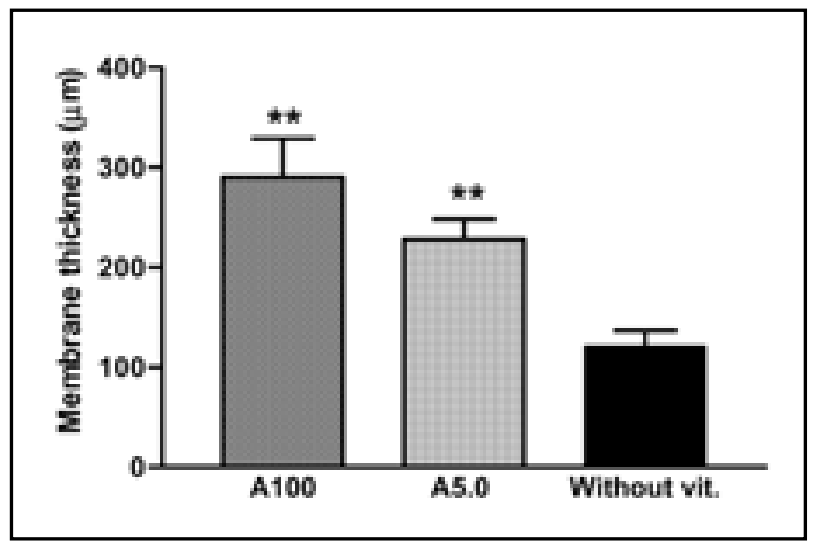

Fig 4. Non-supplemented guinea pigs (full filled bar) showed a reduction in periodontal membrane thickness, as mean of three different measurements (at the alveolar ridge level, at the root intermediate level, and at the most apical radicular level), in comparison to supplemented $A 100$ and $A 5.0$ animals. Difference is significant at ${ }^{* *} p<0.01$ by unpaired Student- $t$ test. Vertical bars indicate the standard error mean.

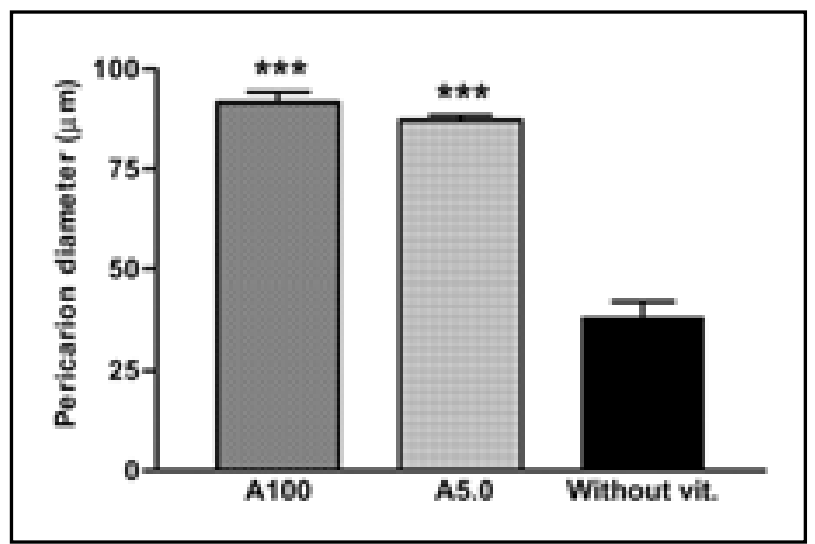

Fig 5. Morphometric study from spinal a-motor neurons showed a conspicuous reduction in perikaryon diameter of $A 0$ specimens in relation to supplemented group. Difference is significant at ${ }^{* * *} p<0.001$ by unpaired Student-t test and by one-way ANOVA. Vertical bars indicate the standard error mean.

\section{Morphology approach (Morphometry)}

Motor neurons - We analyzed the spinal cord slices using a light binocular microscope with millimeter ocular (Leitz Wetzlar Germany Periplan, GF 10x). The slices were stained by cresyl violet technique to detect the basophilic material called Nissl substance in $\alpha$-motor neuron in anterior gray horn. We measured the cell body diameter of 100 spinal motor neurons in a set of five serial cross-sections from each animal $(n=5)$ along the experimental group, searching the most conspicuous ones in great magnification.

Periodontal membrane - We analyzed the periodontal ligament thickness in decalcified tooth stained by Van Gieson and Mallory's trichrome in three different levels: (a) at the level of alveolar ridge; (b) at the root intermediate level; (c) at the most apical radicular level. We examined 100 


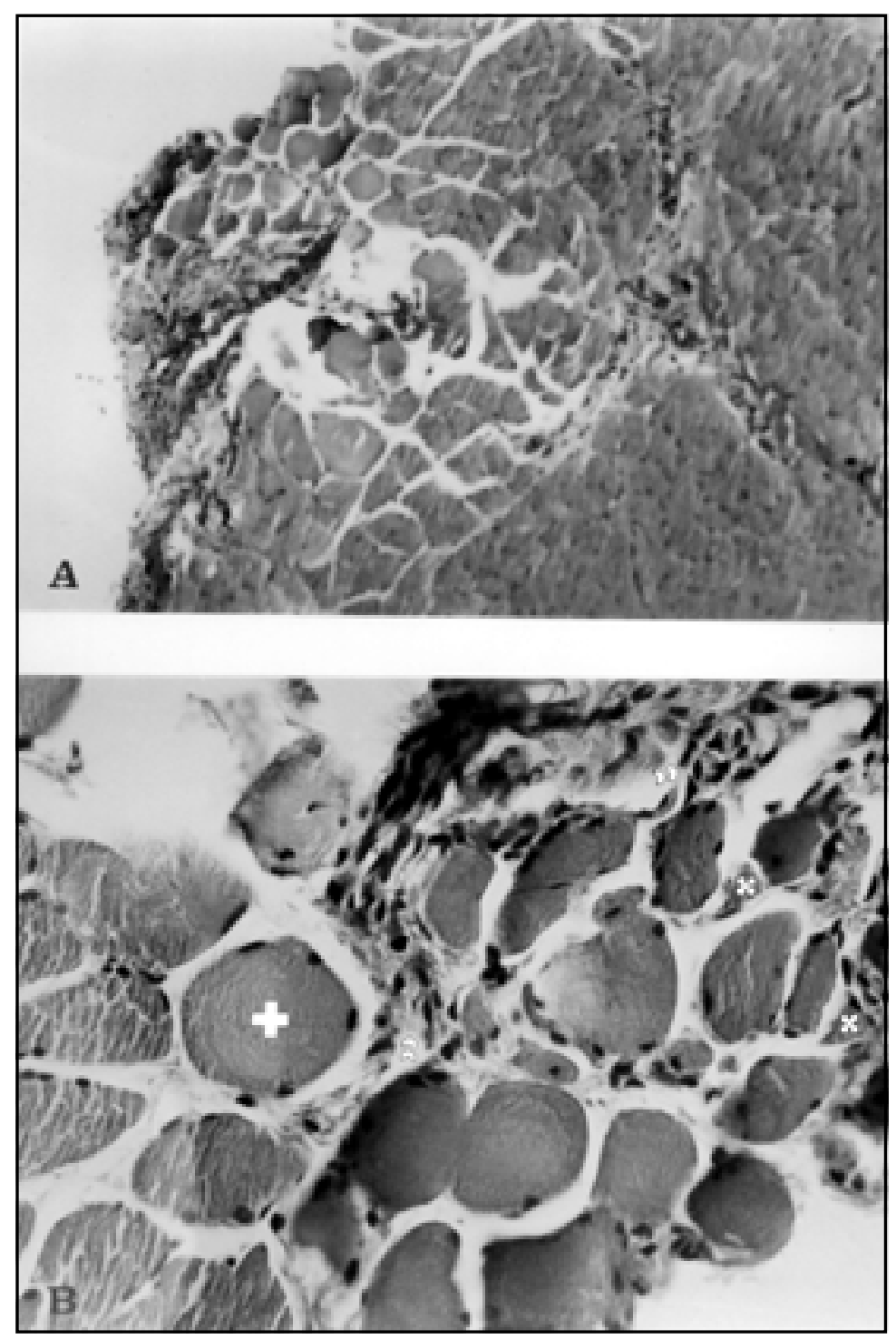

Fig 6. Gastrocnemius muscle from $A 0$ group ( $A$ and $B$ ) (transverse and oblique sections, $H \& E, x 100$ and $x 400$, respectively). Note groups of normal fibres, among them, small groups of atrophic and angular fibres $(X)$ and fibres of greater diameter (+). Some show necrotic pattern (»).

specimens in a set of five serial cross-sections at thoracic level from each animal $(n=5)$ along the experimental group. The mean of these three level measurements was obtained as described above.

Histopathological technique - Tissue samples were obtained post-mortem, fixed in buffered formalin and embedded in paraffin. Six- micrometer-thick sections from the paraffin-embedded blocks were hydrated after removing the paraffin, stained and mounted by entellan medium in glass slides. In the case of Weil's method, 10 micrometerthick sections were used. Hematoxylin-Eosin technique was chosen to study muscle histology, Van Gieson and Mallory' trichrome to tooth specimens, and Weil and cresyl violet to spinal cord samples. The Weil's method was useful to detect the integrity of pyramidal motor tract myelinization.
Statistics - Statistical analysis was performed using GraphPad InStat $^{\mathrm{TM}}$ for MS-DOS and GraphPad Prism ${ }^{\mathrm{TM}}$ for MS-Windows on an IBM-PC. The statistical significance of the differences was analyzed by Student-Turkey and ANOVA for continuous variables. When data violated assumptions for parametric tests, non-parametric Mann Whitney U-test was used. Significance was considered when $p<0.05$.

\section{RESULTS}

Weight gain - The supplemented animals showed weight gain during all the experimental period, in a dose relationship. The scorbutic animals exhibited weight gain just during the first two weeks (until about $12^{\text {th }}$ day), thereafter they showed a remarkable weight loss, especially in the final days of the protocol (Fig 1). 


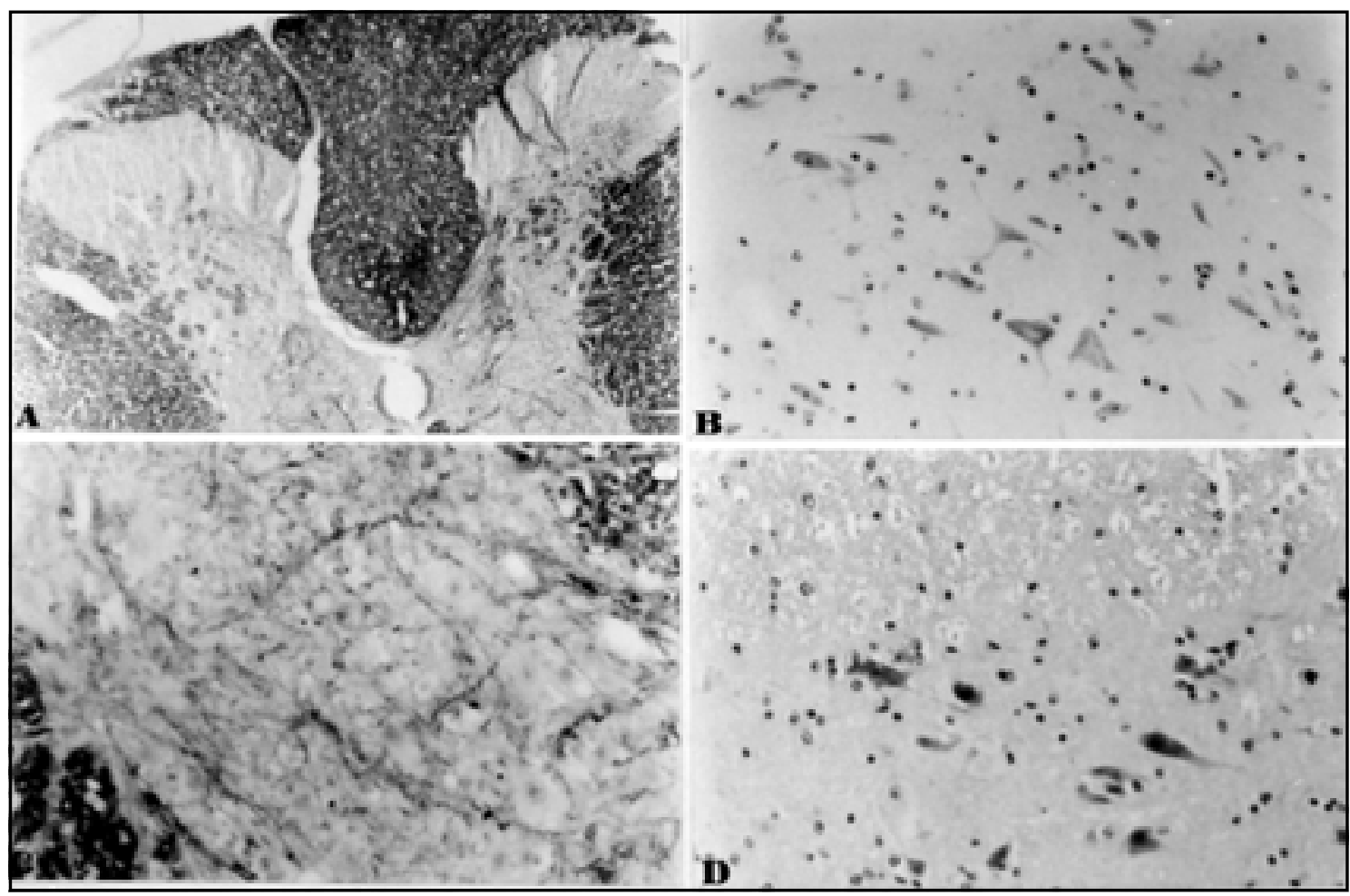

Fig 7.1. Spinal cord from $A 0$ group ( $A$ ) (transverse section, Weil's method, $x 40$ ). Note that the pyramidal tract myelinization is preserved at the base of the posterior funiculus; Spinal cord from $A 0$ group ( $B, C$ and $D$ ) (transverse section of anterior horns, cresyl violet, x100, x100 and 100, respectively). Note a reduction in motor neuron density and gliosis.

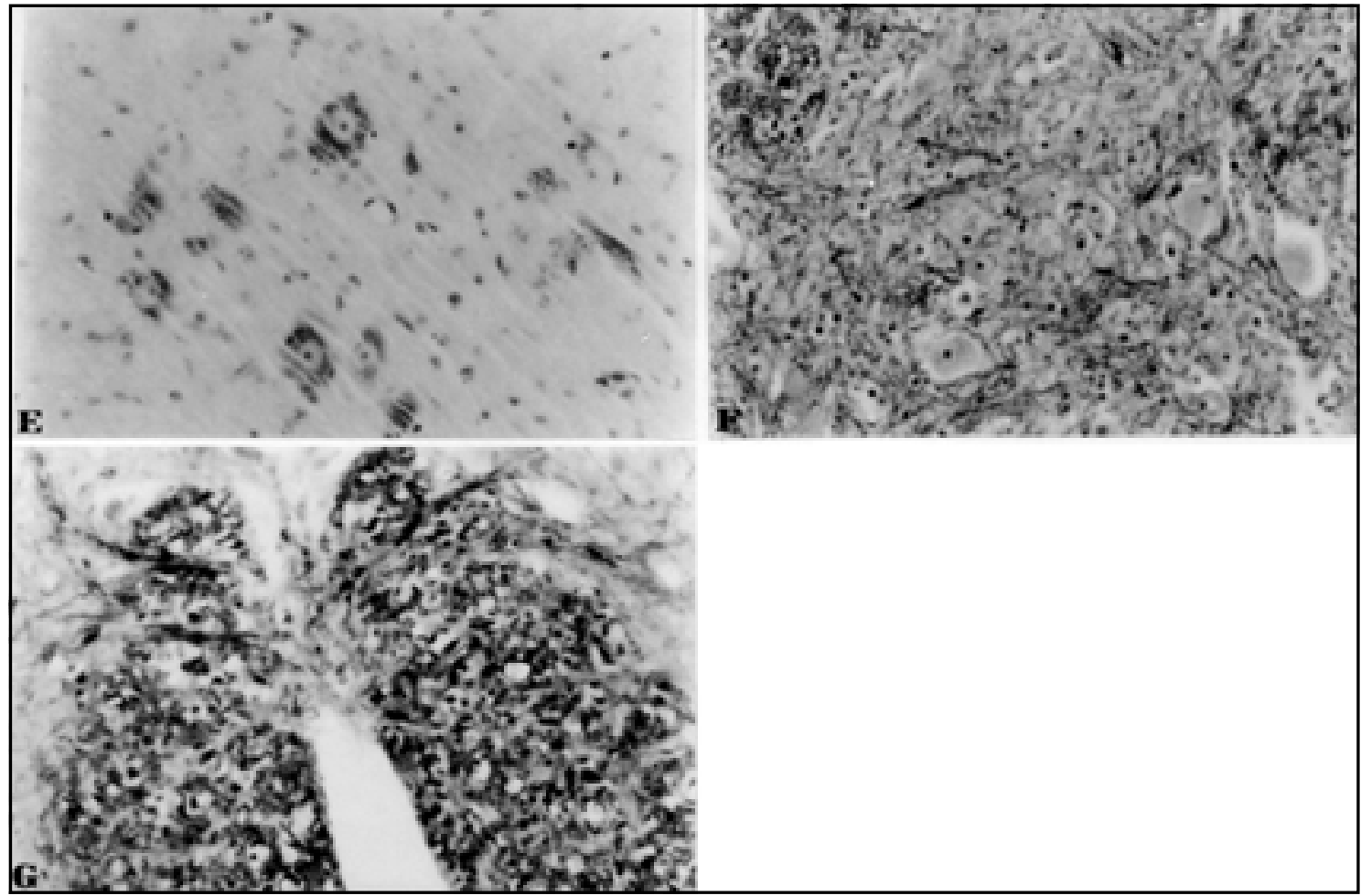

Fig 7.2. Spinal cord from supplemented groups ( $E$ and F) (transverse section, cresyl violet, $x 40$ and $x 100$, respectively); Spinal cord from AO group (G) (transverse section, cresyl violet, $x 400$ ). Note great reduction in body cell diameter in the motor neuron at the left side of the field, and vacuolization of the motor neuron at the right side. 
Clinical state and autopsy findings - Considering the scorbutic rating scale designed for guinea pigs by Verlangieri et al. ${ }^{21}$, clinical signs included hemorrhages, reduction of exploratory behavior in open field, back/neck piloerection, weakness, ataxia, dysbasia and weight changes were in some degree observed particularly in the last days of the experiment. We also detected spontaneous bone fracture and dystrophy frequently in anterior thighs (in a few animals). The autopsy findings confirmed the subcutaneous, subepimysial and joint hemorrhages, further hemorrhagic gastroenteritis, bone and tooth fragility and muscular atrophy were the more obvious clinical features.

Muscular diameter - The supplemented and nonsupplemented animals showed a progressive gain of muscular mass, during the experimental period. However, we detected a significant reduction in right thigh muscular diameter, measured by digital caliper, in the vitamin $C$ deficient animals in the last days of the experiment in comparison with the supplemented groups (Fig 2). The A100 and A5.0 groups showed a mean muscular diameter significantly superior to the deficient group $(p<0.001$ and $p<0.05$, respectively).

Motor behavior examination - We found in scorbutic animals a relevant decrease in motor behavior in comparison to the control groups in all tests examined, which had been corroborated by the prior clinical findings (Fig 3). We noted almost a completely non-existence of running behavior in $\mathrm{A} 0$ animals. A100 and A5.0 supplemented control groups exhibited no significant difference, concerning all motor behaviors studied $(p<0.05)$.

\section{Light microscopy (morphometry)}

Periodontal ligament - The non-supplemented group exhibited a decrease of mean thickness of the periodontal ligament (PL) as compared with $\mathrm{A} 100$ and $A 5.0$ groups ( $p<0.001$ and $p<0.05$, respectively). The periodontal ligament reduction was observed in a variable degree through all its extension since alveolar ridge level until its more apical process (Fig 4).

$\alpha$-motor neurons - We confirmed a significant reduction in the cell body mean diameter of $\alpha$-motor spinal neurons $(p<0.001)$ when compared with the supplemented groups. There was no statistically difference in measurements between $\mathrm{A} 100$ and A5.0 supplemented groups (Fig 5).

\section{Histopathological changes}

Skeletal muscle - The gastrocnemius muscle from scorbutic animals (Figs 6-A and B) appeared atrophied in small groups as compared to controls, exhibiting muscle fibers with irregular shapes, including oval and angular aspects, among hypertrophied ones. Lack of cylindrical cell morphology and normal arrangement were conspicuous in some fasciculi. Indeed, severe reduction of muscle fiber diameter and incompletely cross-striations were also observed. We confirmed micro hemorrhagic areas in supporting tissues.

Spinal Cord - The slices of spinal cord at thoracic level from $\mathrm{A} 0$ animals confirmed the signs of ventral horn motor neuron involvement, as illustrated by chromatolysis features as seen by cresyl violet staining method (Fig 7.1-B and D) as compared to controls (Fig 7.2-E). Furthermore, a relevant number of motor neurons showed cell body diameter decrease and hyaline inclusions (Fig 7.1-B). Some $\alpha$-motor neurons almost totally lack their morphological polarity. Some spinal cord specimens exhibited a reactive gliosis, with marked conspicuous satellitosis. However, the guinea pig pyramidal tract was preserved in A0 subjects as seen by Weil's myelin staining at the level of posterior funiculus of white matter (Fig 7.1-A). The reduction of Weil staining contrast in the gray matter of anterior columns from scorbutic spinal cords revealed decreased cytoplasmatic extensions from motor neurons (Fig 7.1-C) as compared to controls (Fig 7.2-F), unless without complete disappearance. There was no important alteration in comissural white matter neither others fasciculi areas (Fig 7.2-G).

\section{DISCUSSION}

The recent findings about the compartmentalization of brain ascorbate and glutathione (GSH) between neurons and glia indicated that these compounds, because of their antioxidant properties, have great relevance in homeostatic control of oxidative products in $\mathrm{CNS}^{12,22-24}$. These data suggest that ascorbate is predominantly localized in neurons. Their tissue contents are region-specific and in the milimolar range. This scenery renders the crucial role of ascorbate in several physiological and pathological conditions at the vicinity of the CNS. Indeed, it reflects the oxidative metabolism in neurons at mitochondria level. Motor neuron vulnerability to oxidative stress is credited to low intracellular calcium sequestration and high energy dynamics, thus imbalance of free radical buffering by increased pro- 
duction of oxygen species and defective antioxidant capacity, taking together, could undergo toward a growing impairment ${ }^{25}$.

Ascorbate is released from intracellular sites in close association with the glutamate uptake by a heteroexchange mechanism within glutamatergic neurons and glia. This ascorbate delivery in CNS motor tracts under synaptic firing might be neuroprotective. The overall glutamate metabolism seemed to be affected by motor neuron disease, triggering a degenerative process by an amplified loop involving a large number of well documented lethal conditions induced by several enzymatic actions, including endonucleases, NOS and peroxidase pathways, finally leading to membrane lipid peroxidation and cell death ${ }^{17,26}$.

The oxidative motor neuron injury explained the importance of antioxidant network balance both at water and lipid cell phase. Ascorbic acid may be a useful tool in recycling $\alpha$-tochoferol and glutatione radical back to the reduced form as an electron donor in CNS, playing an indirect protective action ${ }^{27}$. Moreover, recent studies have demonstrated that the ascorbic acid is beneficial against peroxynitrite (ONOO-) radical attack, which is closely related to motor neuron damage ${ }^{28,29}$. In addition, GLT-1 glutamate protein carrier system may become jeopardized by oxygen reactive species, thus causing its progressive accumulation on synaptic cleft, over stimulating excitatory aminoacid receptors on post-synaptic dominium.

The guinea pig nutritional model for experimental motor neuron disease, first described by Den Hartog Jager ${ }^{20}$, was strongly argued by Sillevis Smitt \& De Jong ${ }^{30}$, who used a chronic ascorbic acid deficiency protocol and a purified diet containing minimal and defined amounts of $A A$, based on the recommendation of the National Council Research. Their results did not show changes in spinal pyramidal tract, although, they confirmed a nutritional myopathy, complicated by trauma, and arthrogenic factors without apparently signs of anterior horn motor neuron death ${ }^{31}$. These authors suggested that Den Hartog Jager's previous findings were defined from an inappropriate dietary regimen to experimental guinea pigs. Shils ${ }^{32}$ stated the importance of adequate control groups in nutrition studies.

In light of an actual knowledge, the reduction of the net scavenger milieu on spinal cord from scorbutic guinea pigs could be quite intensified by the assumption that, under poor neuron density environments such as those found in more posterior areas of the CNS, there would be diminished vitamin C storage capacity (white matter: gray matter tissue ratio), for extracellular scavenge requirements. In addition, the high metabolic motor nervous cells seemed to be more prone to oxidative insults. Recently, it was confirmed in a G93A transgenic mice model that mutation of SOD1 elevates the level of both $\mathrm{H}_{2} \mathrm{O}_{2}$ and $\mathrm{OH}$ but not in the mice, overexpressing normal human SOD133. Moreover, the combined treatment with trientine, a chelating agent for cooper, and ascorbate had been beneficial in familial amyotrophic lateral sclerosis model mice, with a protective effect on the onset of the disease and its end-point ${ }^{34}$.

Whether the vitamin $\mathrm{C}$ withdrawal had a direct causal action in the motor neuron impairment or whether only had a secondary role in an multifactorial process, we did not know. Our results showed that on scurvy status, the guinea pigs exhibited a motor impairment probably induced by free radical overload and this rich oxidative scenario seemed to trigger the progressive motor neuron jeopardizing, even though without significant motor neuron death, but size reduction and chromatolysis, showing the vulnerability of $\alpha$-motor neuron under vitamin $C$ environmental collapse in the vicinity of nervous tissue. Muscle weakness was linked to clinical carnitine deficiency seen in scurvy ${ }^{35}$.

In our assessment, we choose an intermediate diet, containing vitamin A 10,000 IU/Kg, zinc $0,1 \mathrm{mg} /$ $\mathrm{kg}$, copper $10 \mathrm{mg} / \mathrm{kg}$ and manganese $50 \mathrm{mg} / \mathrm{kg}$. In this chronic deficiency protocol, in turn, we detected an progressive disruption in motor neuron unit, under drastic affected animals, even though, without pyramidal tract involvement. The decline of motor neuron viability seemed to be restricted to spinal cord level, as confirmed by morphometric analysis and histopathological picture, since we did not find important alterations in other CNS regions like cerebral and cerebelar cortices (data not shown). Since there was no apparently sign of pyramidal tract degeneration, which in guinea pigs is localized at the base of posterior column in spinal cord ${ }^{20,31}$, neither upper motor neuron involvement in our protocol, the present results do not support the previous idea of an animal model for lateral amyotrophic sclerosis as described by Den Hartog findings. The decline of all motor skills investigate seemed to be directed related to increasing ascorbic acid default, complicated by a myriad of scurvy outcomes, most of them involving 
skeletal tissues, however, the vitamin C megadosis seemed not to significantly ameliorate the motor abilities tested because there was no important difference in the motor behaviors assisted between both supplemented groups.

Acknowledgment - The authors would like to thank José Ivan Rodrigues de Sousa and Oséas Ribeiro Queiroz for technical assistance and Sílvio Alves Costa for his aid in the electronic typewriting of this manuscript.

\section{REFERENCES}

1. Banhegyi G, Braun L, Csala M, Puskas F, Mandl J. Ascorbate metabolism and its regulation in animals. Free Radic Biol Med 1997;23:793-803.

2. Carr A, Frei B. Does vitamin C act as a pro-oxidant under physiological conditions? FASEB J 1999;13:1007-1024.

3. Ten Cate AR. Oral histology: development, structure and function. St. Louis: Mosby, 1998.

4. Weber P, Bendich A, Schalch W. Vitamin C and human health: a review of recent data relevant to human requirements. Int J Vitam Nutr Res 1996;66:19-30.

5. Cammack J, Ghasemzadeh B, Adams RN. The pharmacological profile of glutamate-evoked ascorbic acid efflux measured by in vivo electrochemistry. Brain Res 1991;565:17-22.

6. Nagel E, Meyer zu Vilsendorf A, Bartels M, Pichlmayr R. Antioxidative vitamins in prevention of ischemia/reperfusion injury. Int J Vitam Nutr Res 1997;67:298-306.

7. Padh H. Vitamin C: newer insights into its biochemical functions. Nutr Rev 1991;49:65-70.

8. Agus DB, Gambhir SS, Pardridge WM, et al. Vitamin C crosses the blood-brain barrier in the oxidized form through the glucose transporters. J Clin Invest 1997;100:2842-2848.

9. GuoZ, Kindy MS, Kruman I, Mattson MP. ALS-linked Cu/Zn-SOD mutation impairs cerebral synaptic glucose and glutamate transport and exacerbates ischemic brain injury. J Cereb Blood Flow Metab 2000;20:463-468.

10. Kok AB. Ascorbate availability and neurodegeneration in amyotrophic lateral sclerosis. Med Hypotheses 1997;48:281-296.

11. Lai YJ, Shen EY, Pan WH. Effects of ascorbate in microdialysis perfusion medium on the extracellular basal concentration of glutamate in rat's striatum. Neurosci Lett 2000;279:145-148.

12. Revuelta M, Romero-Ramos M, Venero JL, Millan F, Machado A, Cano J. Less induced 1-methyl-4-phenylpyridinium ion neurotoxicity on striatal slices from guinea-pigs fed with a vitamin C-deficient diet. Neuroscience 1997;77:167-174.

13. Rice ME. Ascorbate regulation and its neuroprotective role in the brain. Trends Neurosci 2000;23:209-216.

14. Bano S, Parihar MS. Reduction of lipid peroxidation in different brain regions by a combination of alpha-tocopherol and ascorbic acid. J Neural Transm 1997;104:1277-1286.

15. Rothstein JD. Excitotoxic mechanisms in the pathogenesis of amyotrophic lateral sclerosis. Adv Neurol 1995;68:7-20.
16. Wilson JX, Peters CE, Sitar SM, Daoust P, Gelb AW. Glutamate stimulates ascorbate transport by astrocytes. Brain Res 2000;858:61-66.

17. Kang JH, Eum WS. Enhanced oxidative damage by the familial amyotrophic lateral sclerosis-associated $\mathrm{Cu}, \mathrm{Zn}$-superoxide dismutase mutants. Biochim Biophys Acta 2000;1524:162-170.

18. Denmark SJ. Ascorbic acid staining of scorbutic guinea pig incisors. J Dent Res 1966;45:762-767

19. Touyz LZ. Oral scurvy and periodontal disease. J Can Dent Assoc 1997;63:837-845.

20. Den Hartog Jager WA. Experimental amyotrophic lateral sclerosis in the guinea-pig. J Neurol Sci 1985;67:133-142.

21. Verlangieri AJ, Fay MJ, Bannon AW. Comparison of the anti-scorbutic activity of L-ascorbic acid and Ester C in the non-ascorbate synthesizing Osteogenic Disorder Shionogi (ODS) rat. Life Sci 1991;48:2275-2281.

22. Fornai F, Saviozzi M, Piaggi S et al. Localization of a glutathione-dependent dehydroascorbate reductase within the central nervous system of the rat. Neuroscience 1999;94:937-948.

23. Grunewald RA. Ascorbic acid in the brain. Brain Res Brain Res Rev 1993;18:123-133.

24. Rice ME, Russo-Menna I. Differential compartmentalization of brain ascorbate and glutathione between neurons and glia. Neuroscience 1998;82:1213-1223.

25. Gurney ME, Cutting FB, Zhai $\mathrm{P}$, et al. Benefit of vitamin E, riluzole, and gabapentin in a transgenic model of familial amyotrophic lateral sclerosis. Ann Neurol 1996; 39:147-157.

26. De Belleroche J, Orrell RW, Virgo L. Amyotrophic lateral sclerosis: recent advances in understanding disease mechanisms. J Neuropathol Exp Neurol 1996;55:747-757.

27. Martensson J, Han J, Griffith OW, Meister A. Glutathione ester delays the onset of scurvy in ascorbate-deficient guinea pigs. Proc Natl Acad Sci USA 1993;90: 317-321.

28. Noack H, Lindenau J, Rothe F, Asayama K, Wolf G. Differential expression of superoxide dismutase isoforms in neuronal and glial compartments in the course of excitotoxically mediated neurodegeneration: relation to oxidative and nitrergic stress. Glia 1998;23:285-297.

29. Stamford JA, Isaac D, Hicks CA, Ward MA, Osborne DJ, O'Neill MJ. Ascorbic acid is neuroprotective against global ischaemia in striatum but not hippocampus: histological and voltammetric data. Brain Res 1999;835:229-240.

30. Sillevis Smitt PA, De Jong JM, Troost D, Kuipers MA. Muscular changes in the guinea pig caused by chronic ascorbic acid deficiency. J Neurol Sci 1991;102: 4-10.

31. Sillevis Smitt PA, De JongJM. Animal models of amyotrophic lateral sclerosis and the spinal muscular atrophies. J Neurol Sci 1989;91:231-258.

32. Shils ME. The need for adequate control groups in nutrition studies. J Neurol Sci 1991;102:1-3.

33. Liu D, Wen J, Liu J, Li L. The roles of free radicals in amyotrophic lateral sclerosis: reactive oxygen species and elevated oxidation of protein, DNA, and membrane phospholipids. FASEB J 1999;13:2318-2328.

34. Nagano S, Ogawa Y, Yanagihara T, Sakoda S. Benefit of a combined treatment with trientine and ascorbate in familial amyotrophic lateral sclerosis model mice. Neurosci Lett 1999;265:159-162.

35. Hughes RE, Hurley RJ, Jones E. Dietary ascorbic acid and muscle carnitine (beta-OH-gamma-(trimethylamino) butyric acid) in guineapigs. Br J Nutr 1980;43: 385-387. 